Proceedings of the International Conference on Teaching, Education and Learning Conference, Vol. 1, 2021, pp. 87-98 Copyright (C) 2021 iConferences

ISSN 2820-2155

DOI: https://doi.org/10.32789/tel.2021.1007

Socio-Demographic Characteristics, Personality Traits and Stress Level of Senior High School Students

Lord Joseas C. Conwi

De La Salle Medical and Health Science Institute, Philippines, lcconwi@dlshsi.edu.ph 


\title{
SOCIO-DEMOGRAPHIC CHARACTERISTICS, PERSONALITY TRAITS AND STRESS LEVEL OF SENIOR HIGH SCHOOL STUDENTS
}

\begin{abstract}
Students involved with medical school are perceived as stressed because of the difficulties in the field. The study was conducted to determine the relationship between personality traits and stress level as the basis for developing counseling intervention for the students. This study utilized the descriptive correlational method. The study involved 1,003 senior high school students, with ages ranging from 15-20 years old. For the findings, the majority of the students are 16-17 years old. Females outnumbered male students. The average monthly family income was P50,001 to P100,000. Most students were living with two biological parents and one sibling. Senior high school students' dominant personality types are extraversion and agreeableness. Also, the result revealed that the leading stressors centered on academic workload, anxiety, high expectation of parents and environmental concerns. In general, there was no significant relationship between personality traits and stress level. However, it was found that there is a significant positive correlation between the personality trait of neuroticism and the stress level of the students. Moreover, there is a significant negative correlation between the personality traits of extraversion, conscientiousness, and openness and stress level. Meanwhile, there is no significant and negative relationship between the personality trait of agreeableness and stress level.
\end{abstract}

Keywords: Stress level, counseling intervention, development, personality

\section{Introduction}

Mental health is one of the most addressed issues nowadays. Due to increasing rates of suicides and the prevalence of anxiety and depression, especially among youths, a lot of people work hard to raise awareness of this issue. Moreover, students involved with medical school are perceived as being stressed because of the difficulties in the field. In addition, the academic demands required by institution increases every year, resulting in an increased degree of stress. According to Dy et al. (2015), the top stressors of their students are the academic difficulty of subject matter, workload due to subjects, time management because of subjects, responsibilities due to being on one's own, and time management because of both subjects and organizations. According to most high school students, their greatest academic stress includes tests, grades, homework, academic and achievement expectations, and parental pressure. School-related stresses include inadequate instructional methods, teacher-student relationships, heavy academic workload, poor physical classroom environments, inability to balance one's leisure time with school, and disorganization surrounding academic assignments and schedules. Additional sources consist of a struggle to meet academic standards, worries about time management and concerns over grades and scores. Students are thus, seen to be affected by the negative causes of academic stress. Academic and exam stress is found to be positively correlated with parental pressure and psychiatric problems. It is important to remember that the mental constitution or coping capacities vary from one child to another. Therefore, children with 
poor coping abilities become more prone to anxiety, depression, and fear of academic failure, and this shows us that one should not compare one student with another. (Thakkar, 2018).

Like any other students, senior high school students at De La Salle Medical and Health Sciences Institute Special Health Sciences are also experiencing stress which somehow affects their academic performance and psychological make-up. The school envisioned preparing and forming students as future medical and health allied professionals. This means the pressure and expectation arise in students' experience. Thus, it explains the heavy academic workload that senior high school students can experience.

In this regard, the researcher had formulated a study to determine the relationship of personality traits and stress levels of senior high school students to create a counseling intervention that promotes a change of behavior in the side of students to lessen the stressors and a higher level of academic achievement and fewer problems with the physiological and interpersonal relationship in the school.

\section{Objectives of the Study}

Generally, the study sought to determine the relationship between personality traits and the stress level of senior high school students and the basis of the counseling intervention program proposal. Specifically, the study aimed to 1 . Determine the socio-demographic characteristics; 2 . Determine their level of personality traits; 3. Determine their level of stress; 4. Identify the degree of relationship between stress level and personality traits, and 5. Determine a counseling intervention that can be proposed in the school.

\section{Hypothesis}

The following hypothesis was to be tested to accept or reject the proposed study on the relationship of personality traits and stress levels of selected senior high school students in De La Salle Medical and Health Science Institute. Ho1 There is no significant relationship between personality traits and stress level.

\section{Conceptual Framework}

The paradigm reflects the study's main aim on correlating personality traits and stress level and what relationship each has with the other. The conceptual framework was carefully planned by the researcher, envisioning the specific need of the school. In this manner, a counseling intervention will be proposed that fits the needs of the students. 


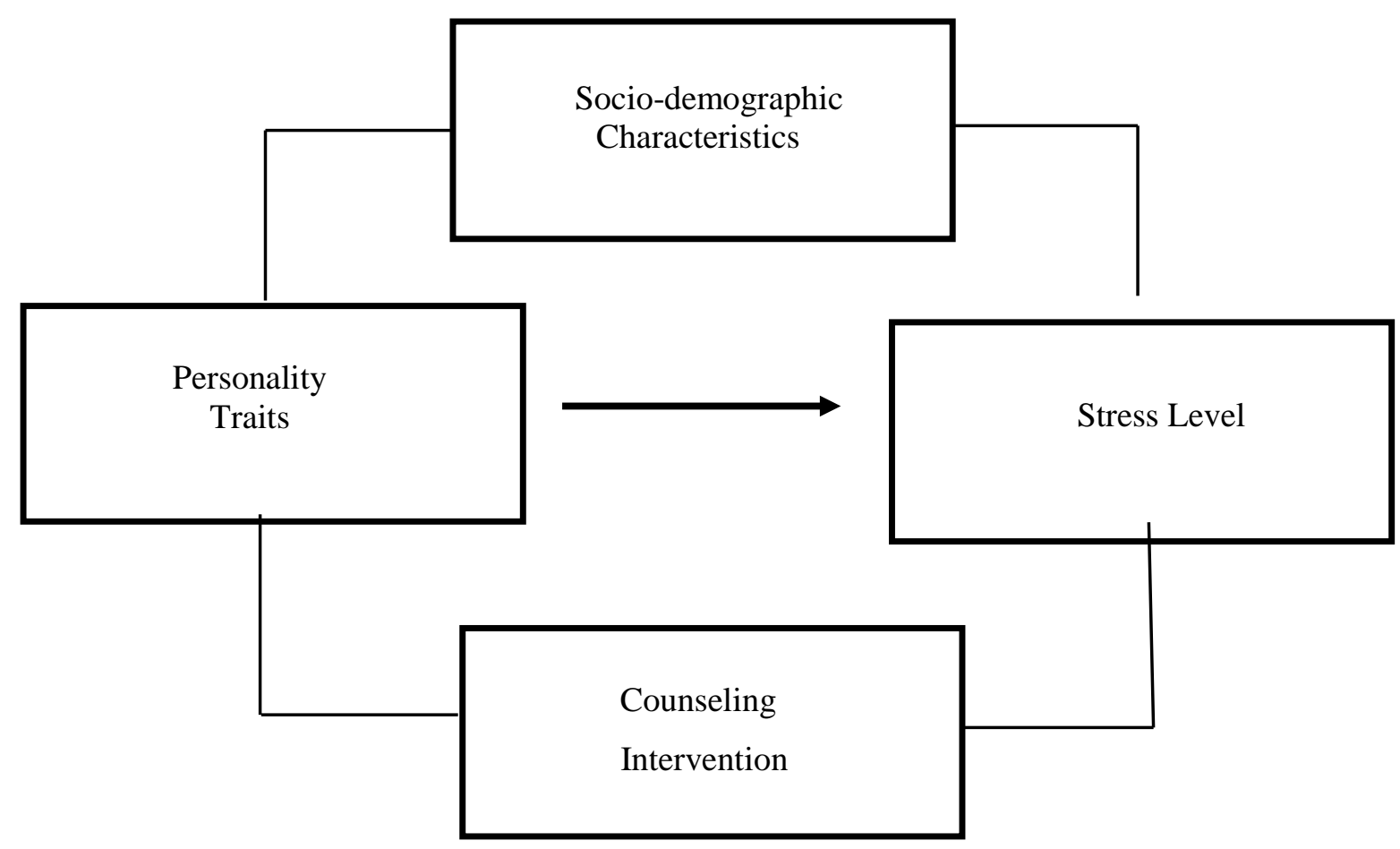

Figure 1. The paradigm of the study

\section{Methodology}

\section{Research Design}

A descriptive correlational research design was used in the study. Descriptive research gathers quantifiable information that can be used for statistical inference to your target audience through data analysis. Particularly, this study sought to determine the socio-demographic characteristics: age, sex, monthly family income, parental structure, number of siblings and birth order. The study also determined if the stress level has a significant relationship to the personality traits of the senior high school students.

\section{Participants}

One thousand and three $(1,003)$ senior high school students from DLSMHSI Senior High School, with ages ranging from 15-20 years old, regardless of sex, were the study participants.

\section{Research Tool}

To measure the variables presented, the researcher administered the following research instruments: Personal Data Sheet. A self-compiled questionnaire consisted of items that gathered information on age, sex, estimated family income, parental structure, and birth order. This identified whom to include and exclude in the study. Individual Personality Inventory Scale (I.P.I.S). Individual Personality Inventory Scale is composed of 45-item questions format with five (5) responses, which identify the Dominant Personality type of the students. Each question falls under the following respective domains of personality. The items for openness to experience are 1, 6, 11, 16, 21, 26, 31, 36, 41. For conscientiousness are $2,7,12,17,22,27,32,37,42$. For extroversion are $3,8,13,18,23,28,33,38$, 
43. For agreeableness are 4, 9, 14, 19, 24, 29, 34, 39, 44. For neuroticism are 5, 10, 15, 20, 25, 30, 35, 40, 45. The Individual Personality Inventory Scale scoring is composed of five responses: 0 - Never, 1 - Rare, 2 - Sometimes, 3 - Often, 4 - Always. In addition, the researcher used Student Stress Inventory, the most widely used psychological instrument for measuring student stress. SSI contained 40 negative items to measure 4 subscales (10 items for each subscale) which are subscale 1: Physical (10 items), subscale 2: Interpersonal relationship (10 items), subscale 3: Academic (10 items) and subscale 4: Environmental factor (10 items). As for scoring, the SSI was designed with the ordinal scale of the 'Never', 'Somewhat frequent', 'Frequent' and 'Always'. The value mark given for each choice is 1 for 'Never', 2 for 'Somewhat Frequent', 3 for 'Frequent' and 4 for 'Always'.

\section{Data to be Gathered}

The standardized instrument used had undergone ethical and regulatory procedures done by the ethics board of De La Salle Medical and Health Science Institute. In addition, the research study was approved by the ethical review board of Cavite State University. Beforehand, the researcher ensured that the instrument and the purpose of the study would not harm the senior high school students in any way or form. Permission to conduct the study was sought from the Director of the De La Salle Medical and Health Science Institute Special Health Science Senior High School through a request letter to conduct the research with the cooperation of their students covered within the age scale of 1520 years old or above as students. This served as a formal agreement signed by the director of their department (Senior High School) after being informed of all the details and conditions regarding the procedure of conducting the study. This included the utilization of a vacant room within their respective university dedicated to the senior high school students to answer the given questionnaires formally and properly as this can also help the proper distribution of papers.

After data collection, the researcher prepared the data to be interpreted, as it was part of data visualization. To create an organized and accurate interpretation of all the data collected, the researcher analyzed the obtained data to determine the relationship between the variables. In this manner, counseling intervention will be developed based on the results and findings of the research made about the socio-demographic, personality traits and stress level. Counseling intervention is defined as helping strategies or counseling method which aims to create a change and provide a positive result in one's environment.

\section{Result and Discussions}

Socio-demographic Characteristics of Senior High School Students. This section presents the frequency and percentage distribution of the socio-demographic profile of the one thousand three $(1,003)$ students of De La Salle Medical and Health Science Special Health Science Senior High School. It includes the age, sex, monthly family income, type of parental structure, number of siblings and birth order. In discussion, most of the students were 16 or younger, with a mean age of 17.09 years. Females have a larger number compared to males. Most of the students' average monthly family income was $\mathrm{P} 50,000$ to $\mathrm{P} 100,00$ and above. The majority of the students lived with two biological parents, had one to two siblings, and were firstborn.

Personality Traits of Senior High School students. Agreeableness was the most leading personality trait portrayed by the senior high school students with a mean of 28.15, followed by extraversion (25.33) and openness (23.61). Lesser students had the personality traits of conscientiousness (23.59) and neuroticism (21.76). Student personality suggests that the majority of the students have dominant 
characteristics of being agreeable, which means they adjust their behavior to suit other people. They are also compassionate and cooperative and prefer to serve in community leadership roles.

Table 1: Level of personality traits of Senior High School students

\begin{tabular}{cccc}
\hline Personality Traits & Mean & SD & Percentage \\
\hline Extraversion & 25.33 & 5.854 & High \\
\hline Agreeableness & 28.15 & 4.493 & High \\
\hline Conscientiousness & 23.59 & 5.818 & Average \\
\hline Neuroticism & 21.76 & 5.968 & Average \\
\hline Openness & 23.61 & 5.335 & Average \\
\hline Total & 24.49 & 5.49 & High \\
\hline Legend: $0-12$ (Low Level) & $13-24$ (Average Level) & & $25-36$ \\
\end{tabular}

Stress Level of Senior High School Students. As to the stress level of students, academics was the leading source of stress among the senior high school students with a mean of 26.97, followed by environment (26.88), physical (25.38), and interpersonal (20.96). Generally, the majority of the students have a moderate level of stress. Students moderate stress levels may be explained by their difficulty in handling tasks and workloads. If not controlled or managed, it may lead to deteriorating factors as they may also have a moderate coping mechanism. Physical stress may cause them to be vulnerable to sickness, while interpersonal stress may affect their social connectedness and in getting along with people.

Based on the study result, Students feel considerable tiredness that hinders them from performing better in their academic responsibilities. Sleep problem is connected to the constant fatigue they are experiencing. With the result of other factors such as environmental, emotional, and family and social pressures. The combination of the aforementioned factors why students feel stress in their academic life results in another stress they should also handle. Also, it shows that interpersonal stress, generated by competing demands of school responsibility and personal factors, decreased the students' academic performance. It was represented most of the senior high school students in terms of the wish of their parents for them to be successful equated with more stress incapable of managing their academic pursuits, which proves that the higher the interpersonal stress, the higher the impact on their mental health. Likewise, Academic stress affects students academically to have bad performance in school. Students experience a lack of concentration. Stress in students can affect the ability to concentrate on difficult subjects; consequently, it interferes with a student's ability to finish academic works. Similarly, most of the students reported moderate to high levels of stress because of environmental factors. Environmental stressors include limited computer and internet access, recreational centers, quality health service, and study rooms, which were found to be among the students' high levels of stress-causing factors.

Table 2: Level of stress of senior high school students

\begin{tabular}{cccc}
\hline Stress Level & Mean & SD & Remarks \\
\hline Physical & 25.38 & 5.712 & Moderate \\
\hline Interpersonal & 20.96 & 4.559 & Moderate \\
\hline Academics & 26.97 & 6.343 & Moderate \\
\hline Environment & 26.88 & 5.961 & Moderate \\
\hline Total & 25.05 & 5.64 & Moderate \\
\hline Legend: 10 - 20 (Mild Stress Level) & $21-30$ (Moderate Stress Level) & $31-40$ & (Severe Stress Level)
\end{tabular}


Personality Traits and Stress Level. As to the relationship between personality and stress level, personality traits had a positive and significant relationship with physical stress and environmental stress. There was a positive and no significant relationship between personality traits and interpersonal stress. Whereas there is a negative and no significant relationship between personality traits and academic stress. Also, there is a positive and significant correlation between personality traits of neuroticism and total stress level, while there is a negative and no significant relationship between personality traits of extraversion, conscientiousness, agreeableness, and openness and total stress level of the students. Thus, personality traits are ingrained into a person's innate personhood and deeply impact how he/she experiences the world. Furthermore, this study shows that personality impacts how students perceive and experience stress.

Table 3: Relationship between personality traits and (Total) stress level

\begin{tabular}{cccc}
\hline PERSONALITY TRAITS & $\begin{array}{c}\text { SPEARMAN } \\
\text { RANK }\end{array}$ & $*$ P-value & REMARKS \\
\hline Extraversion & -0.113 & 0.000 & Reject Ho \\
\hline Agreeableness & -0.005 & 0.870 & Accept Ho \\
\hline Conscientiousness & -0.155 & 0.000 & Reject Ho \\
\hline Neuroticism & 0.511 & 0.000 & Reject Ho \\
\hline Openness & -0.088 & 0.005 & Reject Ho \\
\hline Total & -0.034 & 0.279 & Accept Ho \\
\hline
\end{tabular}

$* \mathbf{p}<$ or $=0.05$ Reject Ho (Significant); $\mathbf{p}>$ or $=0.05$ Accept Ho (Not Significant)

** $r$ of .1 (small effect size); $r$ of .3 (medium effect size), $r$ of .5 (large effect size)

Counseling Intervention. The proposed counseling intervention program focuses on personality enhancement: expressing yourself, self-change activities, peer interactions, and student engagement. Also, the counseling intervention program will give attention to stress reduction, including psychosocial intervention, parents support, the achievement motivation group, and green space intervention.

Table 4: Counseling Intervention Learner's needs

\begin{tabular}{|c|c|c|c|c|c|}
\hline $\begin{array}{l}\text { Learners Needs } \\
\text { (Personality Traits) }\end{array}$ & Activities & Participants & $\begin{array}{l}\text { Delivery } \\
\text { System }\end{array}$ & $\begin{array}{l}\text { Delivery } \\
\text { Mechanism }\end{array}$ & Remarks \\
\hline \multirow{3}{*}{$\begin{array}{l}\text { Openness: Express } \\
\text { yourself activity }\end{array}$} & $\begin{array}{l}\text { Live, Love, Laugh and } \\
\text { Inspire }\end{array}$ & Learners & $\begin{array}{l}\text { Guidance } \\
\text { Curriculum }\end{array}$ & $\begin{array}{l}\text { Meeting via } \\
\text { canvas system }\end{array}$ & \multirow{3}{*}{$\begin{array}{l}\text { Expressing } \\
\text { yourself is one of } \\
\text { the ways will } \\
\text { lessen the stress of } \\
\text { the students thru } \\
\text { creative } \\
\text { interventions. }\end{array}$} \\
\hline & $\begin{array}{l}\text { Kamustahan Session: The } \\
\text { matters of the Heart }\end{array}$ & $\begin{array}{l}\text { Learners } \\
\text { teachers }\end{array}$ & $\begin{array}{l}\text { Guidance } \\
\text { Curriculum }\end{array}$ & $\begin{array}{l}\text { Meeting via } \\
\text { canvas system }\end{array}$ & \\
\hline & $\begin{array}{l}\text { Gunita: Feast of Self- } \\
\text { Love }\end{array}$ & Learners & $\begin{array}{l}\text { Guidance } \\
\text { Curriculum }\end{array}$ & $\begin{array}{l}\text { Meeting via } \\
\text { canvas system }\end{array}$ & \\
\hline
\end{tabular}




\begin{tabular}{|c|c|c|c|c|c|}
\hline \multirow{3}{*}{$\begin{array}{l}\text { Conscientiousness: } \\
\text { Self-Management } \\
\text { activities. }\end{array}$} & $\begin{array}{ll}\text { Understanding } & \text { and } \\
\text { Befriending myself } & \end{array}$ & $\begin{array}{l}\text { Learners } \\
\text { teachers }\end{array}$ & $\begin{array}{l}\text { Guidance } \\
\text { Curriculum }\end{array}$ & $\begin{array}{l}\text { Meeting via } \\
\text { canvas system }\end{array}$ & \multirow{3}{*}{$\begin{array}{l}\text { Being organized, } \\
\text { aligning their } \\
\text { thoughts, and } \\
\text { practising self- } \\
\text { control }\end{array}$} \\
\hline & $\begin{array}{l}\text { Everyone has a story to } \\
\text { share }\end{array}$ & Learners & $\begin{array}{l}\text { Guidance } \\
\text { Curriculum }\end{array}$ & $\begin{array}{l}\text { Meeting via } \\
\text { canvas system }\end{array}$ & \\
\hline & Best Class recognition & $\begin{array}{l}\text { Learners, } \\
\text { teachers, and } \\
\text { administrators }\end{array}$ & Others & Academics & \\
\hline \multirow{3}{*}{$\begin{array}{l}\text { Extraversion: } \\
\text { hope Activities }\end{array}$} & Striving to be Champ & $\begin{array}{l}\text { Learners } \\
\text { teachers }\end{array}$ & $\begin{array}{l}\text { Guidance } \\
\text { Curriculum }\end{array}$ & $\begin{array}{l}\text { Meeting via } \\
\text { canvas system }\end{array}$ & \multirow{3}{*}{$\begin{array}{l}\text { Exercising a sense } \\
\text { of belongingness } \\
\text { and connection }\end{array}$} \\
\hline & Tea Therapy & Learners & $\begin{array}{l}\text { Guidance } \\
\text { Curriculum }\end{array}$ & $\begin{array}{l}\text { Meeting via } \\
\text { canvas system }\end{array}$ & \\
\hline & We are one & Learners & $\begin{array}{l}\text { Guidance } \\
\text { Curriculum }\end{array}$ & $\begin{array}{l}\text { Meeting via } \\
\text { canvas system }\end{array}$ & \\
\hline \multirow{3}{*}{$\begin{array}{ll}\text { Student } & \text { Engagement } \\
\text { Activities } & \end{array}$} & Someone Special & $\begin{array}{l}\text { Learners } \\
\text { teachers }\end{array}$ & $\begin{array}{l}\text { Guidance } \\
\text { Curriculum }\end{array}$ & $\begin{array}{l}\text { Meeting via } \\
\text { canvas system }\end{array}$ & \multirow{3}{*}{$\begin{array}{l}\text { Becoming aware } \\
\text { of the Lasallian } \\
\text { values such as } \\
\text { altruism and } \\
\text { compassion. }\end{array}$} \\
\hline & Dream B. I. G. & Learners & $\begin{array}{l}\text { Guidance } \\
\text { Curriculum }\end{array}$ & $\begin{array}{l}\text { Meeting via } \\
\text { canvas system }\end{array}$ & \\
\hline & $\begin{array}{ll}\text { Lasallian at } & \text { Heart } \\
\text { Outreach Program } & \end{array}$ & Learners & Others & $\begin{array}{l}\text { Social Media } \\
\text { Platforms }\end{array}$ & \\
\hline \multirow{3}{*}{$\begin{array}{l}\text { Neuroticism } \\
\text { Mind Matters }\end{array}$} & Mindfulness Therapy & $\begin{array}{l}\text { Learners and } \\
\text { teachers }\end{array}$ & $\begin{array}{l}\text { Support } \\
\text { System }\end{array}$ & $\begin{array}{l}\text { Meeting via } \\
\text { canvas system }\end{array}$ & \multirow{3}{*}{$\begin{array}{l}\begin{array}{l}\text { Handling } \\
\text { frustration, } \\
\text { anxiety, and } \\
\text { sadness }\end{array} \\
\text { Handling } \\
\text { frustration, } \\
\text { anxiety, and } \\
\text { sadness. }\end{array}$} \\
\hline & All is well & Learners & $\begin{array}{l}\text { Guidance } \\
\text { Curriculum }\end{array}$ & $\begin{array}{l}\text { Meeting via } \\
\text { canvas system }\end{array}$ & \\
\hline & Peer Interaction & Learners & $\begin{array}{l}\text { Guidance } \\
\text { Curriculum }\end{array}$ & $\begin{array}{l}\text { Social Media } \\
\text { Platforms }\end{array}$ & \\
\hline
\end{tabular}


Learners Needs

(Stress Level)
Activities

Pahinga at Ginhawa

Helping hands Stress:

Psychosocial intervention with the assistance of Learners medical personnel
Delivery
System
Delivery
Mechanism
Remarks

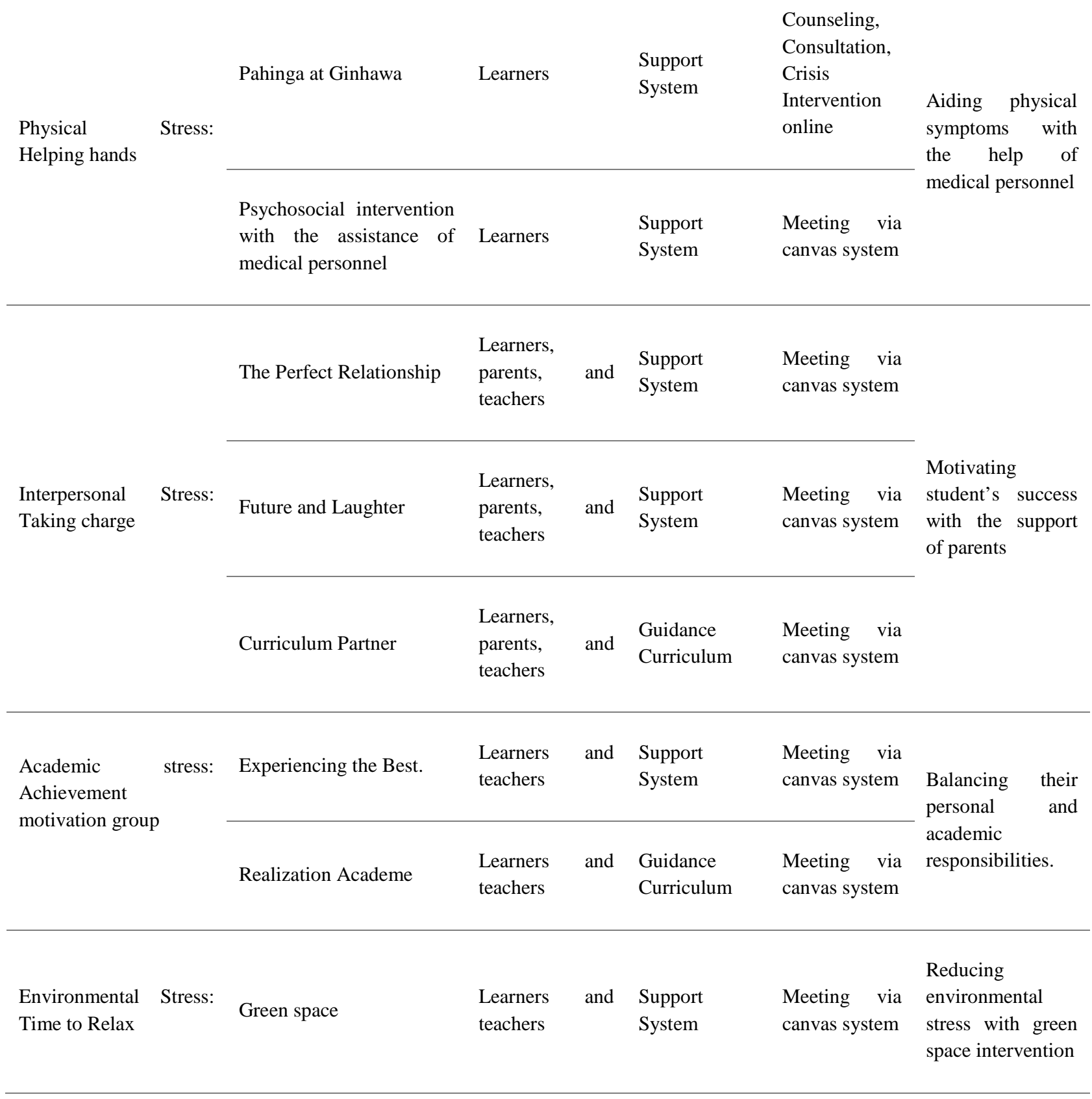


Counseling Intervention Program. This program will be concentrating first on the result area of academic stressors and enhancing the area of agreeableness based on the results and findings of the research made about the socio-demographic, personality traits and stress level. In line with the VisionMission, De La Salle Medical and Health Science Senior High school continually promotes and maintains the quality and standards of education that demonstrate accountability upholding the welfare of everyone. DLSMHSI is committed to developing lifelong learners who possess the ability to become nurturers of life through diverse and meaningful experiences. As they transition to practice, they are equipped to meet the needs of society in the healthcare system.

In this research, the proposed counseling intervention program will focus on two critical areas, which is categorized in personality traits: openness, conscientiousness, extraversion, agreeableness and neuroticism and stress level: physical, academics, social/personal, and environmental. It meets developmental needs, encourages student achievement, resolves personal, behavioral, and social problems, enhances familial relationships, and achieves potential.

This counseling intervention program was designed not just to gain understanding of oneself but for us to uncover our feelings, process our emotions, dig deep into our existence that creates awareness of ourselves for us to change and become a better person as we should be. In light of this research, the researcher could use the result of the study to enhance the existing counseling intervention in the school.

\section{Conclusion}

Based on the results and analysis of the research, the following conclusions were derived:

1. The average monthly family income of the students is $尹 50,001$ to $P 100,000$ is sufficient in studying at medical school. Also, living with two biological parents and having one sibling can be ideal for resources and support. Most of the students are firstborn, which implies the characteristics of being responsible, achievers and sociable.

2. Senior high school students tend to seek out opportunities for social interaction, be approachable, have social confidence and be optimistic. Along with this are the characteristics of altruism, amicable, and overall sensitivity to the needs, which is an indicator of being a Lasallian.

3. The moderate stress level of senior high school students is caused by handling academic workloads and school responsibility. They also have average coping mechanisms resulting in sleeping problems and anxiety. Academic workload, interpersonal relationships and environmental stressors were average. These affect their well-being in many aspects, such as physical, emotional, and psychological health.

4. The students tend to experience stress in terms of physical, interpersonal, academic, and environmental factors when they have a low level of extraversion, conscientiousness, agreeableness, and openness. The students experience more stress when they have a high level of neuroticism. As the students become more creative, open to new ideas, helpful, sociable, enthusiastic, and considerate, the students become less stressed. Similarly, more disciplined students, organized and achievement striving they less suffer from stress. However, students who become very emotionally reactive, unstable, and anxious are likely to suffer from stress. Therefore, if the personality traits of openness, 
extraversion, agreeableness, and conscientiousness increase, stress decreases. Meanwhile, if the personality trait of neuroticism increases, the stress level increases.

5. The proposed counseling intervention program focuses on personality enhancement: expressing yourself, self-change activities, peer interactions, and student engagement. Also, the counseling intervention program will give attention to stress reduction, including psychosocial intervention, parents support, the achievement motivation group, and green space intervention.

\section{Recommendations}

Based on the findings of the study, the following recommendations are suggested:

1. Personality development and stress management are highly suggested in the implementation of the counseling intervention program. Faculty members and the support of administrators may also be involved for this program to be successful.

2. In reducing stress, stress management practices will be the best way to handle such academic burden, specifically in an exceedingly medical school. Moreover, appropriate stress management may help students to become more motivated. Screening students once a year with self-report measures that evaluate stress, depression, and motivation is also helpful. In a parent-teacher relationship, a planned developmental activity to boost parents' understanding of their children; and reduce parents' expectations towards students will help improve their academic life. On the academic side, the administrators may apply measures to enhance instructors' subject matter and pedagogical competence, reducing academic problems and academic overloads. In battling environmental stress, the DLSMHSI community can improve the quality of the learning environment. The concerned bodies possibly can combat these problems specifically, pollution management, well-equipped classrooms, and recreational centers.

3. The guidance and counseling office may strengthen the provision of guidance and counseling services that deal with the mental health problems of their students and subsequently promote their psychological, social, academic, and emotional well-being.

4. Enhanced counseling intervention program will be followed specifically in academic stressors and reducing neuroticism, enabling them to cope with life demands.

5. Future researchers may consider public schools, not only private schools. Also, consider the comparative method of study to see the difference of the result of public-school students to private school students. In addition, a localized standardized instrument can be used to fully assess every student's specific need and address it efficiently. Furthermore, a follow-up study related to the findings can be conducted to support or verify its results. 
Lord Joseas C. Conwi / Socio-demographic characteristics, Personality Traits and Stress Level of Senior High School Students

\section{References}

Dy, Espiritu-Santo, \& Sanchez. (2015). Stressors and stress responses of Filipino college students. Asia Life Sciences. 24. 737-759.

Gadzella, B. M., Pierce, D., \& Young, A. (2008). Development and analyses of the coping stress inventory. College Student Journal, 42(2), 254-264.

Thakkar, A. (2018). Academics stress in students. Retrieved from: https:// medium.com/one-future-academicstress-in-students-498c34f064d7

World Health Organization. (2004). Promoting mental health: concepts, emerging evidence, practice (Summary Report) Geneva: World Health Organization 